\title{
'Voice' languages with no [voice]? Some consequences of Laryngeal Relativism
}

\author{
Eugeniusz Cyran \\ The John Paul II Catholic University of Lublin \\ cyran@kul.pl
}

\begin{abstract}
Strict criteria on phonological categoryhood coupled with strict privativity of representation inevitably lead to a conclusion that sonorants must not contain a prime responsible for voicing. Assuming that this prime is also not supplied to sonorants in the course of phonological derivation, this class of segments, contrary to observed patterns, should be inactive with respect to voicing phenomena. Presonorant sandhi voicing in Cracow-Poznan Polish is used to show how such apparent patterns can be dealt with without compromising the above theoretical assumptions. This however has consequences which bear on almost every aspect of laryngeal phonology. Some of them include: arbitrariness of the relation between phonology and phonetics, emergent nature of laryngeal categories, minimization of the role of phonological computation, re-evaluation of typical analytical criteria for deciding on phonological representation of laryngeal distinctions, which are used in phonological practice, as well as a possibility that the prime [voice], or its theoretical counterpart in various models, is not present in some 'voice' languages.
\end{abstract}

Keywords: Polish voicing; laryngeal relativism; assimilation; phonetic interpretation; phonetics-phonology interface

\section{Introduction}

At the heart of the laryngeal phonology lies the nature of the relationship between phonology and phonetics. While most aspects of phonetics, including the mechanisms producing speech signal, its acoustic structure, and its perception are fairly well established, the shape and size of phonology as well as how it relates to phonetics remains a moot point.

Take, for example, the following two groups of surface observations relating to typical systems with a two-way laryngeal contrast. For our purposes I will call these 'sound patterns' that refer to phonetic facts. It is common analytical practice to assume that such patterns point to particular 'sound systems', that is, particular representations with particular computation. 
(1) Criteria for a type of laryngeal system
a. contrasts 'voiced' obstruents with 'voiceless unaspirated'
b. exhibits FOD (Final Obstruent Devoicing)
c. exhibits RVA (Regressive Voice Assimilation)
d. contrasts 'voiceless aspirated' with 'plain voiceless'
e. may exhibit context-dependent 'passive' voicing of the 'plain voiceless'
f. does not exhibit RVA between obstruents
g. may exhibit progressive devoicing of sonorants

The first three criteria $(1 \mathrm{a}-\mathrm{c})$ are typically associated with 'voice' languages in what has come to be known as Laryngeal Realism to be discussed in more detail in the following section (e.g., Harris 1994; 2009; Helgason \& Ringen 2008; Honeybone 2002; 2005; Iverson \& Salmons 1995; Beckman et al. 2013). These include, for example, Slavic and Romance languages such as Polish, French, Spanish, etc., but also Dutch (Honeybone 2002) and Durham English (Harris 1994), which are Germanic languages. Assuming a privative representation of laryngeal distinctions, which is a wide-spread position nowadays, the 'voice' systems mark the voiced obstruents with feature [voice], or element $|\mathrm{L}|$ and contrast these with the unmarked series. The unmarked obstruents are then either supplied with default properties responsible for voicelessness, or they are directly interpreted as voiceless in phonetic interpretation, as in, e.g., Element Theory (Kaye et al. 1985; Harris 1990; 1994; 2009; Harris \& Lindsey 1995; Backley 2011). FOD is then typically analysed as [voice]/L deletion, while RVA is a case of [voice]/L spreading.

The other criteria (1d-g) point to 'aspiration' languages such as English, or Icelandic. In such systems, voicing of obstruents is said to be passive, that is, involving phonetic influence from the preceding voiced segment when the target obstruent is neutral (e.g., Harris 1994; 2009; Iverson \& Salmons 2003; Jansen 2004; Kohler 1984). This explains the absence of RVA in such systems. The marked series in the 'aspiration' languages possesses [spread glottis], or $|\mathrm{H}|$. Given the criteria in (1), the phonological representation of the contrast is pre-determined: the marked series of obstruents is the one that deviates from the 'plain' voiceless series.

In this paper, I would like to suggest that the criteria in (1) might be wrong with respect to the phonological side, while they fairly accurately describe the phonetic characteristics of the two types of laryngeal sound patterns. First, of all, one must note two types of potential bias in using surface patterns as unambiguous criteria for phonological systems. Both 
types seem to follow from the wish to be able to reach one area (phonetics) from the other (phonology), and vice versa, in an objective and non-arbitrary way

One type of bias may be called the 'what-you-see-is-what-you-get' approach to speech signal. It is reflected not only in assuming that some properties of the signal must be directly associated with an active phonological category, but also, that some properties must not, as will be shown in the following section. Additionally, this approach assumes that observable phenomena, such as FOD, or RVA, which seem to produce alternations, must be given a formal phonological account by means of deletion or spreading of a particular property. The extreme instance of such thinking is, for example, the traditional analytic decision to supply all phonetically voiced objects with a phonological feature [+voice]. This approach has evolved with respect to marking sonorants, first by underspecifying this class - with subsequent default filling during derivation - and eventually, by assuming in some strictly privative models that sonorants remain nonspecified for [+voice], and their phonetic voicing is spontaneous, that is, a by-product of open articulation.

The other type of bias is in fact the reverse of the first one, in that the perspective is now from phonology to phonetics. We may call it the "production bias'. Again, the extreme instantiation of this attitude was the traditional derivational view that phonological computation transforms the abstract phonological representation into the fully specified systematic phonetic level, that is, a representation which is ready for unambiguous phonetic implementation. In other words, the idea was that we needed to somehow get from $/ \ldots /$ to $[. .$.$] through computation. This way of looking$ at the interaction between phonology and phonetics is somewhat relaxed in, for example, Element Theory (ET) and Government Phonology (GP) type of phonological representation (Kaye et al. 1985; 1990; Harris 1990; 1994; Harris \& Lindsey 1995), in that phonological representations are assumed to be phonetically interpretable at any stage of the derivation. This is guaranteed by the nature of the melodic primes called elements. They are abstract cognitive units, and each element is pronounceable independently or in combination with other elements. Phonological computation, on the other hand, merely turns one state of phonological representation into another $(/ \ldots / 1>/ \ldots / 2)$, each of which is interpretable due to the nature of phonological elements. The extent to which ET still suffers from the production bias is visible in the assumption that the elements have universal (and innate) acoustic signatures which facilitate their phonetic interpretation (Harris \& Lindsey 1995). It will be proposed here that this 
vestige of the production bias can be easily eliminated if the acoustic signatures of the elements are allowed to emerge in acquisition. In other words, elements will be viewed as emergent rather than innate (see section 5).

What transpires from the two types of bias and the analytical criteria in (1) is some sort of bi-uniqueness between phonetics and phonology which may be viewed as welcome grounding of phonology in phonetics, but it also seems to involve some undue inflexibility and circularity: a given representation yields particular sound patterns, and particular sound patterns suggest a particular representation. This view, however, does not always work. Instead, I will attempt to show that the phonetic sound patterns in (1) may follow from phonetics, quite irrespective of phonology. In other words, in a 'voice' language like Polish, that contrasts pre-voiced obstruents with voiceless unaspirated ones, some phenomena like FOD and RVA may be due to phonetics alone (cf. Jansen 2007). It will also be suggested that the relation between phonological categories and phonetic ones may and in fact should be arbitrary (section 5).

How do we discover the phonological representation if the criteria in (1) might be wrong? One solution is offered in Kaye (2005) and is called the Phonological Epistemological Principle. It says that the only source of phonological knowledge is phonological behaviour. While most linguists would be prepared to agree with this principle in general, there seems to be no agreement as to what exactly 'phonological behaviour' is. If we replace this dilemma with the question 'what is the function of phonology?', the typical answer would be that phonology provides categorical distinctions (the representational aspect of phonology) and defines the way the categories which express these distinction are manipulated in phonological processing (the computational aspect of phonology). Thus, we may tentatively assume that phonological behaviour involves both the definition of categorical distinctions and how the relevant prime participates in phonological processes.

In this paper, however, I propose that we can really only rely on the first criterion relating to phonological behaviour: definition of categorical distinctions. But even then, the phonological representation cannot be directly read-off from the phonetic form, and the phonological representation of the contrast is by and large arbitrary. The criteria based on computation, on the other hand, need to be viewed with caution if not to be discarded. This follows not only from the fact that FOD and RVA can be given fully legitimate alternative analyses in which no deletion or spreading needs to be evoked, but also from the fact that observable phenomena are generally misleading and contradictory. For example, if phonological be- 
haviour is equated with observable phenomena such as FOD, or RVA, then pre-sonorant voicing, which occurs in Cracow-Poznan Polish (section 3) is also a case RVA and should also be given a formal phonological account based on feature spreading. This would contradict the first criterion defining contrast, which, if taken seriously, precludes a representation of sonorants as possessing [voice]/L.

The problem with sonorant voicing has been noted quite early. Chomsky and Halle (1968) distinguish between the feature [voice] in obstruents and [sonorant] in vowels and sonorant consonants. The proposal of Rice (1993) that the feature [sonorant] be replaced with [sonorant voice] is in the same vain and recapitulates the same problem: sonorant voicing is generally non-contrastive, but sometimes it seems to trigger voicing of obstruents and must be referred to in computation. However, the non-contrastive nature of that feature is problematic, as noted in, e.g., Scheer (2015b). Most standard generative studies of Polish voicing phenomena (Bethin 1984; 1992; Gussmann 1992; Rubach 1996) use [voice] on sonorants for the same purposes, albeit as a default property. However, in those cases where sonorant voicing seems to interact with obstruents, the sonorant defaults must be extrinsically ordered before the obstruent defaults. The element $|\mathrm{L}|$ in Element Theory is also referred to when sonorants seem to interact with obstruents and trigger voicing of the latter. Such analyses can be found in, e.g., Michalski (2008) for Polish. ${ }^{1}$

In what follows, I will adhere to a very restricted definition of phonological behaviour, relating it only to the function of defining categorical distinctions. Since sonorant consonants and vowels do not normally contrast in voicing, I will assume that they never possess [voice]/L. This means that any appearances of active voicing in sonorants must be offered an alternative analysis to phonological spreading. This very strong take of Kaye's Phonological Epistemological Principle will be at the centre of the following discussion. It will also be a yardstick in evaluation of Laryngeal Realism and Element Theory.

As a consequence of the strong assumption about non-voicing of sonorants, it will be shown that Laryngeal Realism does not seem to work for Polish, and a model of Laryngeal Relativism will be proposed in section 4. Its consequences are discussed in section 5. The main claims of that model are that the relation between phonology and phonetics is arbitrary, melodic primes may be emergent, phonological computation is very small, and [voice] is not necessary in a 'voice' language. At the end of the

\footnotetext{
${ }^{1}$ See also Botma $(2004 ; 2011)$ for other languages.
} 
paper I will tackle the problem of incomplete neutralization in Laryngeal Relativism (section 6).

As a starting point of this discussion, we will look closer at Laryngeal Realism, adopting the tenets of Element Theory (Backley 2011; Kaye et al. 1985; Harris 1990; 1994; 2009; Harris \& Lindsey 1995).

\section{Laryngeal Realism and Element Theory}

Laryngeal Realism (Harris 1994; 2009; Helgason \& Ringen 2008; Honeybone 2002; 2005; Iverson \& Salmons 1995) is currently a popular approach to laryngeal phonology. It builds on the observation that there are three phonetic categories along the VOT continuum (Lisker \& Abramson 1964; Keating 1984; Cho \& Ladefoged 1999), that is, fully voiced, plain voiceless and voiceless aspirated $\left(/ \mathrm{b}-\mathrm{p}-\mathrm{p}^{\mathrm{h}} /\right)$. Another relevant observation is that languages with a two-way laryngeal contrast typically utilize the continuum in such a way that one group of languages exploits the first two categories $(/ \mathrm{b}-\mathrm{p} /)$, that is, fully voiced versus voiceless unaspirated, while the other group uses the second and the third category, that is, voiceless unaspirated and voiceless aspirated $\left(/ \mathrm{p}-\mathrm{p}^{\mathrm{h}} /\right)$. Laryngeal Realism is privative in nature and assumes that the voiceless unaspirated series is always unmarked $\mathrm{C}^{\circ}$. On the other hand, the fully voiced obstruents are defined with the phonological category, which is $|\mathrm{L}|$ in ET and [voice] in feature models, while the voiceless aspirated ones possess $|\mathrm{H}|$, or [spread glottis]. ${ }^{2}$

It follows, that languages with a two-way laryngeal distinction divide into 'voice' and 'aspiration' systems, each having the unmarked voiceless unaspirated series as well. The two-element model is able to define a typology with five different systems: a pre-contrast system (2a), in which no laryngeal element is utilized, two different types of two-way systems ('voice' and 'aspiration') in (2b, c), a three-way system, in which both categories are used (2d), and finally, a four-way system, in which one of the series is most complex, as it contains two laryngeal categories in one segment $(2 \mathrm{e})$.

${ }^{2}$ I ignore other phonation types such as glottalization and creaky voice. These might require additional elements, and their discussion would go beyond the scope of this paper. 
(2) 'Voice' and 'Aspiration' languages in a VOT-based typology

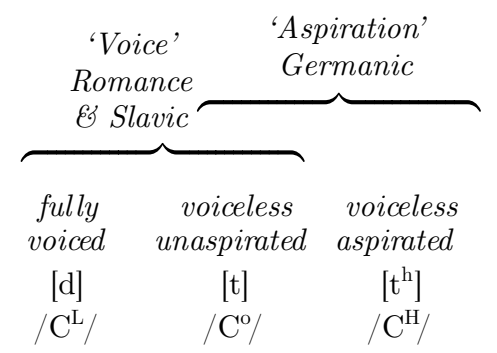
a. Hawaiian
$1-1$
$/ \mathrm{t}^{\mathrm{o}} /$
b. Polish
c. Icelandic
d. Thai
$/ \mathrm{d}^{\mathrm{L}} / \longleftrightarrow / \mathrm{t}^{\mathrm{O}}$
$/ \mathrm{t}^{\mathrm{O}}$
$/ \mathrm{d}^{\mathrm{L}} /$
$/ \mathrm{t}^{\mathrm{o}} /$
$/ \mathrm{d}^{\mathrm{L}} /$
$/ \mathrm{t}^{\mathrm{o}} /$
$\left[\mathrm{d}^{\mathrm{h}}\right]=/ \mathrm{d}^{\mathrm{L}+\mathrm{H}} /$

The predominant practice within Laryngeal Realism is that the phonological representation can be read-off directly from the phonetic signal. Thus, Polish, in which one series has long negative VOT, that is, pre-voicing during closure, is deemed an L-system. English, on the other hand, which has aspiration in strong contexts, can only be an H-system. Thus aspiration and full voicing directly point to the presence of $\mathrm{H} /[$ spread glottis] and $\mathrm{L} /$ [voice] respectively, and can only be due to the phonological presence of these respective categories. This circularity is inherent in the two types of analytical bias mentioned earlier in the Introduction: 'what you see is what you get' and 'production', respectively. This has interesting consequences. For example, Dutch, which is a Germanic language is exceptional in that it must be viewed as a 'voice' system on account of fulfilling the typical criteria listed in $(1 \mathrm{a}-\mathrm{c})$ and failing to fulfil the ones in (1d-g) (e.g., Booij 1995; Honeybone 2002, 293; Iverson \& Salmons 2003; Zonneveld 2007). Honeybone (2002) suggests that Dutch has become 'Romance' with respect to its laryngeal system due to contact with French. That is, it has not just become a 'voice' system on the surface. It must be one phonologically as well.

It is difficult to blame language contact, though, in a similar development in the sociolinguistic variety of English spoken in Durham. It has been singled out as a 'voice' system for the same observational surfacebased reasons as Dutch (Harris 1994, 137-138). The dialect has pre-voicing instead of aspiration, and RVA. For example, top gun is [top g^n] in Standard English is [tob g $\mathrm{n}$ ] in Durham. Clearly, the presence of pre-voicing in plosives and RVA have been taken as indicative of the phonological 
representation because both must involve the presence and spreading of $|\mathrm{L}|$ or [voice], respectively.

A final example of the consequences of realist practice is Swedish, which is quoted as a language with 'over-specification' as it contrasts fully voiced obstruents with voiceless aspirated ones, thus exploiting a maximal dispersion along the VOT continuum (Helgason \& Ringen 2008; Beckman et al. 2011). In Laryngeal Realism both extreme articulations must be represented phonologically as $[$ voice] $/|\mathrm{L}|$ contrasting with $[$ spread glottis $] /|\mathrm{H}|$. Over-specification goes against privativity and the assumption that a minimal contrast (two-way contrast) is preferably minimal, that is, expressed by one category which distinguishes one series from the other. Thus, the Swedish case is problematic for Laryngeal Realism because the system is represented neither minimally nor privatively.

Before we look at Polish data and problems with Laryngeal Realism when sonorants are unspecified for L/[voice], let us consider the way voicing is viewed in ET. Element Theory recognizes three types of voicing (Harris 1994; 2009; Cyran 2014).

(3) Three types of voicing in ET: voicing continuum

\begin{tabular}{|c|c|c|c|}
\hline \multicolumn{2}{|c|}{ spontaneous voicing } & passive voicing & active voicing \\
\hline \multicolumn{2}{|c|}{ universal phonetic principles } & $\begin{array}{c}\text { universal and systemic } \\
\text { principles of phonetic interpretation }\end{array}$ \\
\hline $\mathrm{V}^{\mathrm{o}}$ & $\mathrm{S}^{\mathrm{o}}$ & $\mathrm{C}^{\mathrm{o}}$ & $\mathrm{C}^{\mathrm{L}}$ \\
\hline vowels & sonorants & \multicolumn{2}{|c|}{ obstruents } \\
\hline unconditioned & contextually & $\begin{array}{c}\text { systemically and } \\
\text { condextually } \\
\text { conditioned }\end{array}$ & $\begin{array}{c}\text { phonologically } \\
\text { conditioned }\end{array}$ \\
\cline { 2 - 4 } & $\begin{array}{c}\text { 'aspiration' systems } \\
\left(\mathrm{C}^{\text {o }} \text { vs. } \mathrm{C}^{\mathrm{H}}\right)\end{array}$ & $\begin{array}{c}\text { 'voice' systems } \\
\left(\mathrm{C}^{\mathrm{o}} \text { vs. } \mathrm{C}^{\mathrm{L}}\right)\end{array}$ \\
\hline
\end{tabular}

The table above illustrates what can be called a voicing continuum in that it shows types of voiced segments, with relation to their phonological marking and place in particular linguistic systems. Harris (2009) in fact refers to these aspects as 'disunity of voice', stressing the fact that this phonetic property has a different linguistic status in different segments and systems. The voicing in sonorants $\left(\mathrm{V}^{\mathrm{o}}, \mathrm{S}^{\mathrm{o}}\right)$ is universally spontaneous. It is due to universal phonetic principles (aerodynamics). This voicing does not require any phonological marking at any stage and in any language or special phonetic interpretation statements. Sonorant consonants may be contextually unvoiced, especially between voiceless obstruents, e.g., Polish krtań [krtan] 'larynx', płci [pwtci] 'gender.GEN.SG.', or between a voiceless 


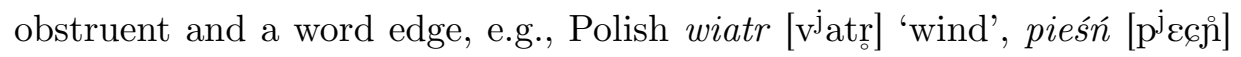
'song'. On the other hand, in the class of obstruents voicing is system dependent and may or may not be backed by $|\mathrm{L}| /[$ voice]. Passive voicing is typically observed in unmarked obstruents $\left(\mathrm{C}^{0}\right)$ in 'aspiration' systems rather than in voicing ones (Kohler 1984; Harris 1994; 2009; Iverson \& Salmons 1995; Avery \& Idsardi 2001). It is, then, a context-dependent phonetic realization of a 'lenis' obstruent (e.g., English). ${ }^{3}$ Finally, active voicing in obstruents is connected with the presence of an active category $\left(\mathrm{C}^{\mathrm{L}}\right)$, and can be found in 'voice' languages like Polish, Spanish or French.

\section{Problems with Polish as an L-system}

Before we look at the relevant Polish data a clarification is in order. At this stage of the discussion the data are introduced in a traditional way, and do not include any information on the incompleteness of neutralization (IN) in FOD and RVA in Polish, which has been found by some researchers (Slowiaczek \& Dinnsen 1985; Strycharczuk 2012a;b). It is not only the question how, but also whether phonology should somehow encode the fact that delaryngealization seems to leave some residual cues to voicing in FOD and RVA. Similar findings concern German (Port et al. 1981; Port \& O'Dell 1985), Dutch (Ernestus 2000), Catalan (Dinnsen \& Charles-Luce 1984). However, there seems to be also an ongoing methodological debate concerning these findings. For example, Jassem and Richter (1989) and Fourakis and Iverson (1984) seem to have found that the neutralization is complete in Polish and German, respectively, pointing also to methodological flaws of some IN studies. Additionally, while with more and more research the body of evidence seems to tip in favour of incomplete neutralization (e.g., Röttger et al. 2014), there are critical voices among phoneticians concerning the validity of the Laboratory Phonology programme and studies in incomplete neutralization in particular (Kohler 2007; 2012). I return to this issue after the main proposal has been made, as some aspects of Laryngeal Relativism are compatible with the experimental findings, while others may still need to be phonologically expressed in some way, not necessarily in categorical terms.

Laryngeal Realism deems Polish a 'voice' language because it fulfils all the criteria in $(1 \mathrm{a}-\mathrm{c})$. It is a language in which the fully voiced obstruents

${ }^{3}$ Although passive voicing does not normally occur in 'voice' systems, it is possible in neutralizing contexts, e.g., in intervocalic position (Hualde \& Nadeu 2011; Scheer 2015a,b). 
are marked with $|\mathrm{L}|\left(\mathrm{C}^{\mathrm{L}}\right)$, while the voiceless unaspirated ones are neutral $\left(\mathrm{C}^{\circ}\right)$ (4a). In ET, the neutral obstruent is phonetically interpretable as it is, and does not require any default filling.

(4) Basic voicing facts in Polish and Laryngeal Realism ${ }^{4}$

a. Two-way voicing contrast in Polish

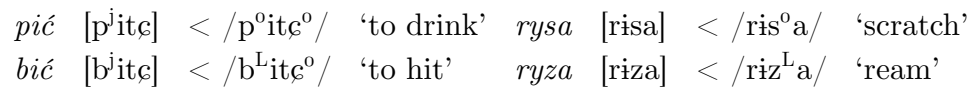

b. Final Obstruent Devoicing (FOD) $\mathrm{C}^{\mathrm{L}} \rightarrow \mathrm{C}^{\mathrm{o}} / \ldots$

$$
\begin{aligned}
& \text { waga } \sim \text { wag 'scale.NOM.SG./GEN.PL.' } \\
& / \operatorname{vag}^{\mathrm{L}} \mathrm{a} />[\text { vaga }] \sim[\operatorname{vak}]</ \operatorname{vag}^{\mathrm{O}} / \leftarrow / \operatorname{vag}^{\mathrm{L}} / \\
& \text { koza } \sim \text { kóz 'goat.NOM.SG./GEN.PL.' } \\
& / \mathrm{koz}^{\mathrm{L}} \mathrm{a} />[\mathrm{koza}] \sim[\mathrm{kus}]</ \mathrm{kuz}^{\mathrm{o}} / \leftarrow / \mathrm{kuz}^{\mathrm{L}} /
\end{aligned}
$$

c. Regressive Voice Assimilation (RVA), $\mathrm{C}^{\mathrm{L}} \rightarrow \mathrm{C}^{0} /{ }_{-}$; $\mathrm{C}^{\mathrm{o}} \rightarrow \mathrm{C}^{\mathrm{L}} / \mathrm{C}^{\mathrm{L}}$

$$
\begin{aligned}
& \text { prosić } \sim \text { prośba 'to ask/a request' } \\
& / \text { pro6 }^{\circ} \text { itc }^{\mathrm{O}} />\text { [procitc] } \sim \text { [prozba] }</ \operatorname{proc}^{\mathrm{L}} \mathrm{b}^{\mathrm{L}} \mathrm{a} / \leftarrow / \operatorname{proc}^{\circ} \mathrm{b}^{\mathrm{L}} \mathrm{a} / \\
& \text { dech } \sim \text { tchu 'breath.NOM.SG./GEN.SG.' } \\
& / \mathrm{d}^{\mathrm{L}} \varepsilon \mathrm{x}^{\mathrm{o}} />\quad[\mathrm{d} \varepsilon \mathrm{x}] \sim[\mathrm{txu}]</ \mathrm{d}^{\mathrm{O}} \mathrm{x}^{\mathrm{o}} \mathrm{u} / \leftarrow / \mathrm{d}^{\mathrm{L}} \mathrm{x}^{\mathrm{O}} \mathrm{u} / \\
& \text { kwiat begonii 'begonia flower' [kf ad begənji] }</ \mathrm{kf}^{\mathrm{j}} \mathrm{at}^{\mathrm{L}} \mathrm{b}^{\mathrm{L}} \text { egənji/ }
\end{aligned}
$$

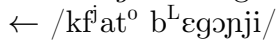

$$
\begin{aligned}
& \text { stóg siana 'heystack' [stuk cana] }</ \text { stug }^{\circ} 6^{\circ} \text { ana } / \leftarrow / \text { stug }^{\mathrm{L}} 6^{\circ} \text { ana } /
\end{aligned}
$$

FOD involves L-delinking (4b), that is, delaryngealization, which leads to neutralization of the distinction seen in (4a). ${ }^{5}$ Regressive Voice Assimilation, as shown by the first two examples in (4c) is symmetrical in the sense that the assimilation to the following obstruent may result in a voiceless ([tx]), or voiced ([zb]) cluster. It is generally assumed that in Polish obstruents lose their laryngeal specification word-finally and before other obstruents (Bethin 1984; 1992; Gussmann 1992; 2007; Rubach 1996). This delaryngealization is a condition for RVA to take place, which means that the target of assimilation is always neutral $\mathrm{C}^{0}$. It should be noted that in a privative model the symmetrical phenomenon of RVA in fact receives an

${ }^{4}$ In what follows, the following symbols are used: '>' = 'phonetically interpreted as', ' $\leftarrow$ ' = 'is phonologically transformed into'. The only two phonological process observed here are L-delinking and L-spreading.

${ }^{5}$ The context involved in delaryngealization is phonologically weak. In GP terms, it occurs before an empty nucleus, which is a weak licenser. The same context applies to the delaryngealization leading to RVA in (4c), that is, an empty nucleus which is itself followed by an obstruents (Cyran 2014, 158). For simplicity, I illustrate the contexts in a traditional way, that is, as _\#, and _ C, respectively. 
asymmetrical phonological description. In words like [txu] (4c) there is only L-delinking and the cluster $\mathrm{C}^{\circ} \mathrm{C}^{0}$ is phonetically interpreted as voiceless without the need to spread anything. This is because there is no property to spread. On the other hand, in [prozba], it is assumed that L-spreading takes place. Across word boundaries, the analysis is essentially the same: we witness L-spreading in [kfjad begonji] and mere L-delinking in [stuk cana]. It should be emphasized that, unlike in binary systems, in privative models of representation some surface instances of assimilation are not due to spreading of a property. We will return to this observation in due time, suggesting that spreading might be absent in all observable cases of voice assimilation.

The data in (4) are common to all varieties of Polish. There is however another phenomenon of supposed assimilation which is problematic for Laryngeal Realism. It concerns the Cracow-Poznan dialect (CPP), as opposed to Warsaw dialect (WP) and consists in pre-sonorant voicing in sandhi. ${ }^{6}$ While both dialects exhibit RVA in the context of the following word-initial voiced obstruents as can be seen in (4c) and (5c, d) below, the two dialects part ways when the second word begins with a vowel or sonorant consonant $(5 \mathrm{e}, \mathrm{f})$. WP retains the voiceless obstruent wordfinally, regardless of the lexical identity, while CPP voices both types of obstruents.

(5) Pre-sonorant sandhi voicing

\begin{tabular}{|c|c|c|c|c|c|}
\hline & Lexical & & WP & $\mathrm{CPP}$ & \\
\hline a. & $\operatorname{sad}^{\mathrm{L}}$ & \# & $\mathrm{t}$ & $\mathrm{t}$ & 'orchard' \\
\hline b. & brat $^{0}$ & \# & $\mathrm{t}$ & $\mathrm{t}$ & 'brother' \\
\hline c. & $\operatorname{sad}^{\mathrm{L}}$ & \# $\mathrm{b}^{\mathrm{L}}$ abci & d & $\mathrm{d}$ & 'grandmother's orchard' \\
\hline d. & brat $^{\circ}$ & $\# b^{L}$ abci & $\mathrm{d}$ & d & 'grandmother's brother' \\
\hline e. & $\operatorname{sad}^{\mathrm{L}}$ & \# ojca & $\mathrm{t}$ & $\mathrm{d}$ & 'father's orchard' \\
\hline$f$ & brat $^{\circ}$ & \# ojca & $\mathrm{t}$ & d & 'father's brother' \\
\hline
\end{tabular}

It is noteworthy that Laryngeal Realism fully predicts the facts from WP. In this dialect, the RVA in sandhi is restricted to the context in which the following word begins with a segment containing $|\mathrm{L}|$. Since sonorants, it will be recalled, must not possess $|\mathrm{L}|$, voicing is impossible in $(5 \mathrm{e}, \mathrm{f})$, which is correct. At the same time, [sat jjtsa] in WP (5e) has FOD as in (4b) and (5a).

${ }^{6}$ The phenomenon is known from other languages as well: Slovak (Bárkányi \& G. Kiss 2015), Breton (Ternes 1970), West Flemmish (De Schutter \& Taeldeman 1986), Catalan (Wheeler 1986), as well as varieties of German and Italian (Krämer 2001). 
Given the main assumptions and practice within Laryngeal Realism, it follows that in CPP, the pre-sonorant sandhi voicing observed in $(5 \mathrm{e}, \mathrm{f})$ is inexpressible unless one resorts to marking sonorants, including vowels, as possessing $|\mathrm{L}|$ in that dialect (Michalski 2008). ${ }^{7}$ Thus, the strict criterion on the presence of a laryngeal category (defining a categorical distinction) is relaxed in the face of observable assimilation, which calls for a phonological account.

A solution to this problem, proposed in Cyran $(2011 ; 2014)$ is a radical break with the Laryngeal Realism, and especially with the bi-uniqueness bias which forces an analyst to treat all Polish dialects as an L-system on account of the criteria in $(1 \mathrm{a}-\mathrm{c})$ and to encode RVA only as L-spreading. It is proposed that there is no direct and objective relation either way between full voicing of obstruents and $|\mathrm{L}|$. And likewise, there is no such relation between aspiration of obstruents and $|\mathrm{H}|$. In other words, there is no a priori and system independent objective relation between full voicing and aspiration and their phonological encoding as $|\mathrm{L}|$ and $|\mathrm{H}|$ respectively. Consequently, the criteria in (1) may still be viewed as correct, but only in describing laryngeal patterns in phonetic terms. The phonological system that stands behind these patterns is to be established, not assumed.

\section{Laryngeal Relativism}

Laryngeal Relativism (Cyran 2011; 2014) began with the observation that there is an interesting and meaningful variation in the way the so-called 'aspiration' languages utilize the phonetic categories along the VOT continuum. Comparing such languages as Icelandic and English one observes that there is a relationship between the phonological robustness of aspiration and the occurrence of passive voicing in the unmarked series. It must be stressed that the term 'phonological robustness' refers only to the distribution ability with respect to relatively strong and weak positions within a word, and not to absolute values of VOT in the two languages. While in English aspiration is best observed before stressed vowels and is rather restricted in other positions in the word, in Icelandic it is realized in more contexts, to the extent that in some positions it takes the form of preaspiration. At the same time, while passive voicing of the unmarked series is common in English, it is very rare in Icelandic (Gussmann 2009, 53).

${ }^{7}$ Interestingly, Gussmann (2007), who believed in universal non-specification of sonorants, simply notes the existence of pre-sonorant voicing, and does not provide a phonological analysis of this phenomenon. 
Crucial in the argumentation for Laryngeal Relativism is the concept of 'phonetic distance', which is expressed symbolically with a dashed horizontal line in (6). In phonetic theory, there are a number of proposals dealing with how phonetic space is utilized with respect to the choice and arrangement of phonetic categories within particular dimensions. If the three phonetic categories along the VOT dimension correspond to the idea of quantal regions in (Stevens 1972), the phonetic distance between two contrasting categories along a particular dimension corresponds to the concept of sufficient dispersion (Liljencrants \& Lindblom 1972; Schwartz et al. 2007). ${ }^{8}$

In the graph below, the placement of the black and white circles symbolizes the phonetic categories utilized in a given system. Black circle is the phonetic category which is at the same time phonologically marked. The white circle is the unmarked series. Thus, in 'voice' systems such as Polish, Spanish and French, the fully voiced obstruents are marked (6a). The unmarked objects are systemically disallowed to undergo passive voicing in positions in which the laryngeal distinction is maintained, that is, in strong positions, because this would undermine the phonetic distance between the two contrastive phonetic categories: it would be difficult to produce and perceive a contrast between a fully voiced and partly voiced obstruents. However, as noted in, e.g., Hualde \& Nadeu (2011); Scheer (2015b), or Schwartz (2016), passive voicing is not precluded in such systems.

(6) Variation in VOT continuum

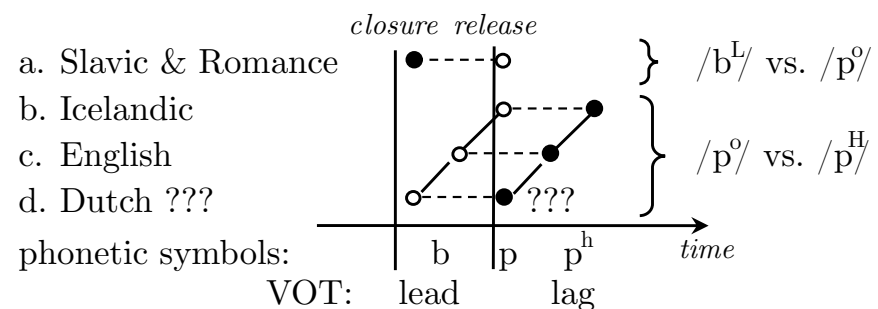

The variation that we are interested in is illustrated in $(6 \mathrm{~b}, \mathrm{c})$. The idea is that the propensity to undergo passive voicing corresponds to the phonological robustness of aspiration in that system. The robustness of aspiration in Icelandic is expressed symbolically by shifting the black circle more

${ }^{8}$ It is sufficient dispersion that is most probably responsible for the fact that systems with extreme laryngeal contrasts like Swedish are exceptional rather than typical. 
to the right in the VOT lag space. ${ }^{9}$ Thus, the phonetic distance between two contrastive series is quite important, as it may be used to understand surface variation. It should be emphasized, however, that the variation concerns not only the phonetic realization of the unmarked (passive voicing), but also of the marked. Thus, what is important in contrast-preserving contexts is that the phonetic distance is maintained between the two series. If in such contexts, for some reason, aspiration cannot be realized, then the distance is maintained by shifting both surface realizations to the extent that they no longer coincide with their supposed phonological marking. In English, intervocalic lenis stops may exhibit voicing throughout the closure, while the fortis series are voiceless unaspirated (e.g., Docherty 1992, 34).

Given the apparent interaction between phonetic distance and robustness of aspiration in the observed variation, it may be claimed that perhaps the exceptional languages like Dutch have gone even further in relativizing the relation between phonetic aspiration and the phonological category $|\mathrm{H}|$. It could be an $\mathrm{H}$-system with no aspiration. This entails the hypothesis that phonetic distance enforces a greater distinctiveness of the unmarked than just passive voicing - the phonologically neutral series could be fully voiced (6d). In other words, an H-system would in fact resemble a 'voice' system (6a), in that the same phonetic categories are utilized as in 'voice' systems, but with the opposite phonological encoding.

One immediate advantage of the shift in (6d) is that Dutch would essentially remain a Germanic language phonologically speaking, but possess Romance phonetic categories. Then, if language contact is to blame for the exceptionality of Dutch, it only had an effect on the phonetic interpretation of the same (Germanic) phonological representation. However, this move is possible only if automatic universal interpretation of $|\mathrm{H}|$ as aspiration is rejected. ${ }^{10}$ The other consequence of this idea is that full voicing in languages like Dutch would have to be viewed as phonologically empty. It is a result of phonetic interpretation of an unmarked object which has to keep sufficient phonetic distance from the marked series which happens to be plain voiceless.

${ }^{9}$ This does not mean that aspiration in Icelandic is more robust phonetically in terms of VOT duration. On average, both languages exhibit the values between 40-80 ms (Beckman et al. 2011).

10 This is easier to envisage in Element Theory, in which elements are defined in terms of gross acoustic patterns, than if feature theories, in which [spread glottis] unambiguously defines aspiration. 
How is such a system possible? The answer is that it is in fact predicted once we free phonological analysis of the criteria in (1) and the two types of bias that follow from the bi-unique way of looking at the interaction between phonology and phonetics. Looking at phonology from the perspective of acquisition rather than production, all that needs to be assumed to arrive at (6d) is that the learner works out the phonetic categories of her language and relations between them in a given phonetic dimension. This provides the learner of a 'voice' language with a two-way distinction among obstruents. Assuming that such minimal contrast requires minimal marking, the learner assigns a distinctive category to one of the two series on the basis of how the whole system operates. While the choice is not really arbitrary for the learner, it may appear to be arbitrary to the linguist because now the fact that a given language is a 'voice' system does not pre-determine which of the two series is actually marked. The division into 'voice' and 'aspiration' languages is now purely phonetic, which of course poses the question how such a system is learned. On what basis do learners select the right category. In Cyran (2014), it is suggested that the presence of such phenomena as CPP sandhi voicing in pre-sonorant context helps make the right decision, while additional phonetic evidence is yet to be established. Or, in fact, if Laryngeal Relativism is right, there should not be any phonetic evidence, only phonological and systemic. More consequences of (6d) follow below.

Cyran (2011) proposed that the two phonetically identical but phonologically opposite systems in (6a) and (6d) in fact correspond to the distinction between Warsaw Polish and Cracow-Poznan Polish. WP is a true 'voice' system, that is, a 'voice' language with the voiced series marked $\left(\mathrm{C}^{\mathrm{L}}\right.$ vs. $\left.\mathrm{C}^{\mathrm{o}}\right)$, while $\mathrm{CPP}$ is a false 'voice' system. In fact, it is at the same time also a false 'aspiration' system in that it contrasts $\mathrm{C}^{\mathrm{o}}$ with $\mathrm{C}^{\mathrm{H}}$, but does not show aspiration. ${ }^{11}$

(7) Contrast: WP vs. CPP

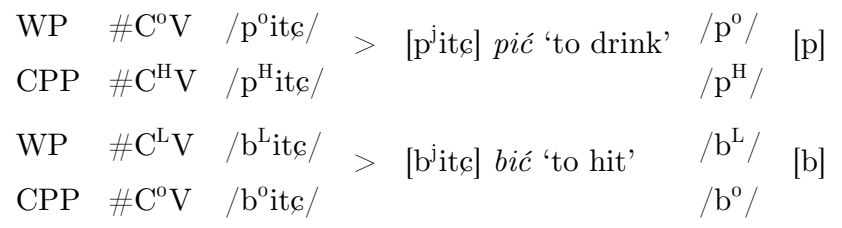

${ }^{11}$ I continue to use the elements $|\mathrm{L}|$ and $|\mathrm{H}|$ as convenient labels, though their status would need to be slightly redefined to deprive them of innate substance, but not of acquired substance. 
The full voicing in CPP obstruents is referred to as 'enhanced passive voicing' in Laryngeal Relativism. The term is purely descriptive and expresses the fact that firstly, such obstruents exhibit more robust voicing than passive voicing known from the literature (e.g., Jansen 2004; Kohler 1984), in that they require similar active articulatory gestures as those present in active voicing, though they are not related to an active phonological category. However, phonetically speaking enhanced passive voicing of CPP is identical to active voicing in WP, because we are dealing with the same phonetic category: pre-voicing. Thus, enhancement, here, does not have any formal phonological status as in, for example, Stevens \& Keyser (1989), or van der Hulst (2015).

Given the distinction in the phonological representation of the two dialects of Polish, the two phonetically identical systems in (7) will make very different predictions about the phonological behaviour of the two series of obstruents. Firstly, if the system $\mathrm{C}^{\mathrm{H}}$ vs. $\mathrm{C}^{\mathrm{o}}$ has FOD, which the 'voice' languages typically exhibit, it will not be a direct result of delaryngealization, because the voiced obstruents have no voicing category to lose. Thus, FOD will have to receive an alternative analysis. Likewise, if such a system has regressive assimilation of voicing (RVA), it will not be due to $|\mathrm{L}|$ spreading.

Let us look at the way Laryngeal Relativism deals with FOD and RVA. To see this, let us make an assumption that computationally WP and CPP are identical in that they have a process of delaryngealization word-finally, and in pre-obstruent position (8). ${ }^{12}$ It is worth noting that the term 'delaryngealization' is also becoming less obvious in Relativism. We might be talking about some other property of phonological representation that leads to the effects which we describe as laryngeal. I maintain the elements and the term to avoid undue confusion at this stage. ${ }^{13}$

(8) Computationally WP and CPP are identical: delaryngealization in $-\left\{\begin{array}{l}\# \\ \mathrm{C}\end{array}\right\}$

a. L-delinking in WP

$$
\mathrm{C}^{\mathrm{L}} \rightarrow \mathrm{C}^{\mathrm{o}} /-\left\{\begin{array}{l}
\# \\
\mathrm{C}
\end{array}\right\}
$$

b. H-delinking in CPP

$$
\mathrm{C}^{\mathrm{H}} \rightarrow \mathrm{C}^{\mathrm{O}} /-\left\{\begin{array}{l}
\# \\
\mathrm{C}
\end{array}\right\}
$$

${ }^{12}$ We leave the problem of incomplete neutralization aside. It will be dealt with in the following discussion.

${ }^{13}$ What is meant by non-laryngeal categories which may be used phonologically to express the laryngeal distinctions are familiar categories like 'fortis' vs. 'lenis' (e.g., van der Hulst 2015), 'tense' vs. 'lax' (Jessen 1998), or phonologically meaningful subsegmental architecture, (e.g., Schwartz 2013; 2016; Pöchtrager \& Kaye 2013). 
It will be noted that FOD is of a different linguistic nature in the two dialects. In WP, it is a formal loss of $|\mathrm{L}|$. In $\mathrm{CPP}$, on the other hand, the loss of $|\mathrm{H}|$ has no direct bearing on FOD because it is delinked from the representation which is already voiceless. In fact, in this dialect, there is nothing that can formally stand behind FOD. The final devoicing must receive a different interpretation, for example, one in which the enhanced passive voicing is impossible if the relevant object $\left(\mathrm{C}^{0}\right)$ is not licensed by a vowel word-finally, the obstruent is in a weak licensing position, which cannot support the phonetic interpretation which is found in strong/prevocalic contexts. Thus, in CPP, FOD is a case of non-voicing rather than devoicing (cf. Harris 2009). This phenomenon is thus given a viable alternative analysis. One which is more phonetic, or interpretational in nature than phonological. ${ }^{14}$ And if correct, it defies criterion (1b): the presence of observable FOD is not a criterion for positing $|\mathrm{L}|$ in a 'voice' language.

RVA is also neatly expressible in the opposite systems of Laryngeal Relativism. In fact, in some respects it is much less problematic than FOD. In the graph in (9), I deliberately do not mark 'spreading' with the conventional association line from trigger to target. Instead, the label is left in inverted commas. This is to emphasize the fact that the assimilations do not really require spreading. Given that the forms involve delaryngealization, the assimilations themselves can be easily provided a non-computational phonetic (co-articulatory) treatment. The only computational mechanism would be, like in the case of FOD, delaryngealization alone.

As can be seen in (9), the opposite marking in WP and CPP yields identical, though mirror image treatment of RVA. It will be recalled from the discussion of (4c) that RVA in a privative model like Laryngeal Realism has two phonological sources. One is mere delaryngealization resulting in a sequence of two unmarked segments. Their interpretation is voiceless in an L-system. In WP, the analysis of RVA is the same, as shown in (9b). Delaryngealization in CPP is observed in $(9 \mathrm{c})$. Here, the $|\mathrm{H}|$ is delinked before an obstruent and both are now non-specified. Since the right-hand side obstruent is followed by a vowel it is to be phonetically interpreted as fully voiced in an $\mathrm{H}$-system like CPP (enhanced passive voicing). It will be recalled that both WP and CPP are 'voice' languages phonetically speaking. The assimilation $/ 6 \mathrm{~b} />[\mathrm{zb}]$ may now be given a phonetic

${ }^{14}$ It is possible to assume that H-delinking facilitates FOD in the sense that the loss of the distinctive category means that the obstruents in final position no longer have to be made distinctive in phonetic interpretation. Similarly, the absence of FOD in some 'voice' languages (e.g., French, Hungarian) might be the result of stronger licensing in word-final position, resulting in contrast maintenance. 
(9) Regressive Voice Assimilation in WP and CPP

Warsaw Polish

a. 'L-spreading'

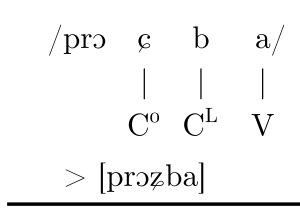

b. L-delinking

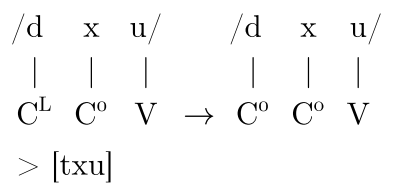

Cracow-Poznań Polish

c. H-delinking

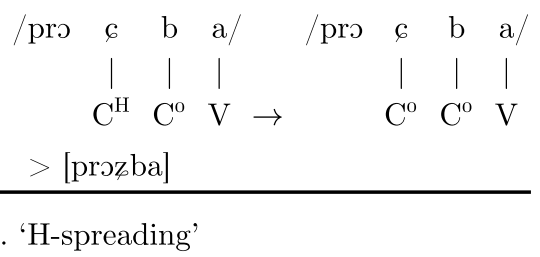

$$
\begin{aligned}
& \begin{array}{ccc}
d & \mathrm{x} & \mathrm{u} / \\
\mid & \mid & \mid \\
\mathrm{C}^{\mathrm{o}} & \mathrm{C}^{\mathrm{H}} & \mathrm{V} \\
> & {[\mathrm{txu}]}
\end{array}
\end{aligned}
$$

interpretation as co-articulatory in nature. ${ }^{15}$ Since pre-vocalic $\mathrm{C}^{0}$ in $\mathrm{CPP}$ is pronounced with active gestures - it is a fully voiced obstruent - such analysis is possible.

So far, we have looked at one half of the assimilations in Polish. The only phonological process involved is delinking of the laryngeal element $|\mathrm{H}|$ or $|\mathrm{L}|$, depending on the dialect. The interpretation of the string $\mathrm{C}^{\circ} \mathrm{C}^{\circ} \mathrm{V}$ is different in the different dialects due to the opposite marking and respective phonetic interpretation relations. It must be borne in mind then, that the phonetic interpretation (spell-out) of the neutral obstruent $\mathrm{C}^{\mathrm{o}}$ is system dependent. Turning now to $(9 \mathrm{~d})$, in which the phonological string is $\mathrm{C}^{\circ} \mathrm{C}^{\mathrm{H}} \mathrm{V}$, the typical treatment would be to spread $|\mathrm{H}|$ to the preceding $\mathrm{C}^{\circ}$. This, however, would be completely superfluous. In tchu [txu] < $/ \mathrm{d}^{\mathrm{O}} \mathrm{x}^{\mathrm{H}} \mathrm{u} /$ 'breath.GEN.SG.', the lexically 'voiced' obstruent, which in fact is neutral $\mathrm{C}^{\circ}$, will not be able to be phonetically interpreted as voiced even if $|\mathrm{H}|$ did not spread. It will be recalled that the enhanced passive voicing requires a following vowel, as in the nominative dech [dex] $</ \mathrm{d}^{\mathrm{O}} \mathrm{ex}^{\mathrm{H}} /$ 'breath.NOM.SG.'. The non-spread analysis of RVA is also available for Lsystems (9a). Here, the situation is parallel to $(9 \mathrm{c})$ in that the sequence $\mathrm{C}^{\mathrm{L}} \mathrm{V}$ produces a fully voiced object (active voicing), which requires active gestures. These enforce identical co-articulation on the preceding obstru-

15 Jansen (2007) argues that co-articulatory (anticipatory) assimilation is possible even if no phonological category stands behind voicing of the trigger obstruents. What is important is that there are active articulatory gestures leading to pre-voicing in the trigger. 
ent. Thus, assimilation does not require any category to spread. Additionally, it appears that it does not matter which of the two series is marked. All instances in (9) are due to phonetic interpretation and one process of preobstruent delaryngealization. Such an analysis would be very much in the spirit of denying the what-you-see-is-what-you get practice. The phonetic criteria in $(1 \mathrm{a}-\mathrm{c})$ describe phonetically induced patterns not phonological systems. They do not point to a particular phonological behaviour.

The non-spread analysis of RVA is clearly a simplification of laryngeal computation, but it has an interesting theoretical consequence too. It paves the way for alternative representations of laryngeal distinctions. Namely, the phonological representation need not rely on spreadable categories (autosegments) to account for assimilations. These options, however, will not be pursued in this paper.

Turning now to the CPP sandhi voicing in pre-sonorant context, it receives a straightforward analysis in Laryngeal Relativism. Firstly, since both lexically voiced and voiceless obstruents are realized as voiced before the following sonorant, it is assumed that the two classes are first delaryngealized as in (8), whereby the word-final obstruents are $\mathrm{C}^{0}$ in both dialects. However, there is a systemic difference between the two dialects with respect to the status and phonetic interpretation of $\mathrm{C}^{\circ}$. In WP, it may be voiced only if the following word begins with an $|\mathrm{L}|$ as in brat babci [brad baptci] $</$ brat $^{0} \mathrm{~b}^{\mathrm{L}}$ abtci $/(5 \mathrm{~d})$. Since sonorants are deprived of $|\mathrm{L}|$, no voicing of $\mathrm{C}^{0}$ occurs in this dialect in pre-sonorant context (10a). The word-final obstruent is neutral either lexically, or as a result of L-delinking, and receives an interpretation as voiceless unaspirated in WP, very much as it does word medially, e.g., bratu [bratu] $</$ brat $^{0} \mathrm{u} /$ 'brother.DAT.SG.'. Thus, the answer why WP does not feature pre-sonorant voicing is that in this system an obstruent can be voiced when it possesses $|\mathrm{L}|$, or when it is followed by an actively voiced segment, like in the assimilation in (9a).

(10) WP vs. CPP and sandhi voicing before sonorants

a. WP

$$
\begin{aligned}
& \text { /brat }{ }^{0} \text { \# ojtsa/ }>\text { [brat ojtsa] 'father's brother' } \\
& \text { L-delinking } \\
& / \operatorname{sad}^{\mathrm{L}} \# \text { ojtsa } \rightarrow / \operatorname{sad}^{0} \# \text { ojtsa } />\text { [sat ojtsa] 'father's orchard' } \\
& \left./ \operatorname{sad}^{0} \# \text { ojtsa/ } \quad>\text { [sad ojtsa }\right] \\
& \text { H-delinking } \\
& \left./ \text { brat }^{\mathrm{H}} \text { ojtsa } / \rightarrow \text { brat }^{\mathrm{O}} \# \text { ojtsa/ }>\text { [brad jjtsa }\right]
\end{aligned}
$$

b. CPP 
In CPP (10b), the non-specified $\mathrm{C}^{0}$ now finds itself in the phonetic context in which it is regularly interpreted as voiced inside words, e.g., sadu [sadu] $</ \operatorname{sad}^{0} \mathrm{u} /$ 'orchard, gen.sg.'. Thus, CPP pre-sonorant sandhi voicing is an interpretational and phonetic rather than phonological phenomenon. No special rule is required except for word-final delaryngealization, which is assumed to be common to both dialects.

This analysis does not predict intervocalic voicing to occur wordinternally because in this context, the so-called voiceless obstruents in CPP retain their $|\mathrm{H}|$, e.g., mapa $\left[\right.$ mapa] $</$ map $^{\mathrm{H}} \mathrm{a} /$ 'map'. For intervocalic voicing to occur, this context would have to be weakening in a given language. It is not in Polish. Thus, H-delinking occurs word-finally, and only in this context do we observe pre-sonorant voicing in CPP. Although, technically, it is not voicing, but phonetic interpretation of the unmarked in a phonetically voiced context. At this point, we are able to suggest that the 'voice' languages which show or historically showed intervocalic voicing, e.g., Western Romance (Scheer 2015b), might well be false 'voice' systems of the type CPP is.

This analysis is to some extent compatible with that proposed for Slovak in Bárkányi \& G. Kiss (2015), henceforth B\&K. They also agree that pre-sonorant voicing requires neutralization of the laryngeal contrast in word-final position, and therefore, a 'targetless' obstruent with respect to laryngeal gestures. The latter may to some extent correspond to our $\mathrm{C}^{\mathrm{o}}$. This way, the authors maintain, we can see a connection between FOD and pre-sonorant voicing. Unfortunately, the neutral $\mathrm{C}^{0}$ is not sufficient to get pre-sonorant voicing. WP has delaryngealization (FOD), and therefore, targetless obstruents, but no voicing in front of sonorants occurs in sandhi in this dialect. Thus, there are other factors determining the presence or absence of pre-sonorant voicing. Delaryngealization is certainly only one of them, but not the only one. What is no less important is the function that the phonologically neutral $\mathrm{C}^{0}$ plays in the interpretative system in question. Pre-vocalically, it is voiceless in WP and voiced in CPP in Laryngeal Relativism due to the fact that the same 'voice' language is allowed to have different systems, that is, opposite phonological marking and respective phonetic interpretation to go with it. $\mathrm{C}^{\mathrm{O}}$ is not universally targetless, it seems.

One additional problem that can be noted with respect to the conclusions in B\&K is the authors' suggestion that pre-sonorant voicing must have been somehow phonologized 'on a par with pre-obstruent voicing' 
(op.cit., 88). ${ }^{16}$ Given the central claim in our discussion - that there is no such thing as phonological voicing in sonorants - phonologization of presonorant sandhi voicing is untenable, regardless of which direction this voicing would actually come from. B\&K rightly note that the voicing in pre-sonorant context is very much passive, that is, perseverative. It is a case of post-voicing. The source can be located in the preceding vowel. At the same time, Slovak, as well as both dialects of Polish have FOD, which means that passive voicing in word-final context is not sufficient, and the context of the following sonorant consonant or vowel is crucial in sandhi voicing. That is why the phenomenon is called pre-sonorant sandhi voicing. The pre-sonorant context, at the same time, seems to be dubious both phonologically, due to non-specification of sonorants for voice, and phonetically. Sonorants, including vowels, do not involve any active gestures which might influence articulatory planning of the type observed in front of actively voiced obstruents.

I would like to propose a solution to this conundrum. The claim that pre-sonorant context does not involve any laryngeal planning may be too strong. First, let us note that plosives in Polish tend to be released wordfinally. It is difficult to assess, linguistically speaking, which cues are aimed for and which could be a by-product of other articulatory targets. Thus, release burst could be the aim or a result of other articulatory gestures just as well. Nevertheless, release burst in final position entails a number of gestures such as raised glottis, which is the case in the voiceless obstruents in Polish (Wierzchowska 1971, 154), sometimes constricted glottis with raising, stiffening of the walls of the vocal tract, and so on. It appears then, that there may be some articulatory planning when the neutralized obstruents are, say, utterance final. ${ }^{17}$ And these gestures militate against voicing. This is why all dialects of Polish, as well as Slovak have FOD.

The pre-sonorant 'planning' in CPP and Slovak may therefore be viewed as absence of the above mentioned utterance-final planning. To use the language of Laryngeal Relativism, the string $\mathrm{C}^{\mathrm{O}} \#$ Sonorant is treated by phonetic interpretation on a par with word internal $\mathrm{C}^{0}+$ Sonorant. In other words, for the phonetic interpretation purposes, the word boundary is irrelevant. It may, of course, be claimed, that in WP, the situation

${ }^{16}$ In fact, B\&K do not make it clear what exactly causes pre-sonorant voicing: whether it is passive post-voicing, or pre-sonorant phonologized assimilation, what exactly is phonologized, and how.

17 This planning has been taken by some linguists as a case of word-final fortition (Iverson \& Salmons 2007). The idea that FOD may be a case of strengthening is criticised in Harris (2009). 
is different. Namely, the word boundary is relevant for articulatory planning, the final stops must be released, and therefore become voiceless both utterance-finally and in pre-sonorant position. It remains to be seen if this is correct. Surely, FOD concerns also affricates and fricatives which do not end in a release burst. However, RVA before voiced obstruents does occur in WP, which suggests that active gestures influence articulatory planning even across the word boundary in this dialect. It is therefore important to stress that even if WP ignored word boundaries, and the spell-out domain was the same as in $\mathrm{CPP}$, that is, $\mathrm{C}^{\mathrm{o}} \#$ Sonorant rather than just $\mathrm{C}^{\mathrm{o}} \#$, the phonological system of WP in Laryngeal Relativisms would still not allow for pre-sonorant voicing. This is because the obstruent in $\mathrm{C}^{\mathrm{o}}+$ Sonorant must be voiceless in this dialect. We may call this effect an interpretational active voicelessness. That is, gestures are employed which disallow passive voicing, and even more so, enhanced passive voicing.

This brings us to an important issue of the difference between passive voicing known from the literature (e.g., Iverson \& Salmons 2003; Jansen 2004; Kohler 1984), and the enhanced passive voicing proposed in this paper. Most authors agree that the directionality of passive voicing is from left to right. In other words, passive voicing is perseverative. It is also suggested (Jansen 2004; B\&K) that this type of voicing affects targetless obstruents which involve no laryngeal planning in their articulation. However, the enhanced passive voicing in $\mathrm{CPP}$ is conditioned from the right hand context, a difference that requires an explanation (cf. Scheer 2015). The term 'enhanced passive voicing' was coined, infelicitously perhaps, in contrast to 'active voicing'. This is because both terms describe the same phonetic reality: a fully voiced obstruent in a 'voice' language, with active gestures, which lead to pre-voicing word-initially. However, we are dealing with distinct phonological and systemic realities. While active voicing involves the presence of the phonological category $|\mathrm{L}|$ or [voice] (WP), enhanced passive voicing corresponds to an unmarked $\mathrm{C}^{\circ}$ in an $\mathrm{H}$-system that also produces a 'voice' language (CPP). Thus, 'passive' merely means 'not active phonologically' here. The term 'enhanced', on the other hand, is meant to distinguish this type of voicing from phonetic passive voicing. It means that the phonetic interpretation of the neutral $\mathrm{C}^{0}$ which is a direct translation (spell-out) of the phonologically unmarked object involves active articulatory gestures, unlike in passive voicing. Thus, 'enhancement' does not take the form of phonological default rules as in, e.g., Stevens \& Keyser (1989), or van der Hulst (2015). It has no phonological function, but it has the systemic function: in pre-sonorant context, the non-specified $\mathrm{C}^{\mathrm{o}}$ is interpreted phonetically in the same way as word-medially. 
The directionality of the conditioning of enhanced passive voicing, which is from right to left, is due to the relation between phonetic interpretation and phonology. Enhanced passive voicing is different from both passive voicing and from enhancement as understood in the literature. It is an interpretative (spell-out) phenomenon, which may occur in CPP but not in WP, hence the different effects in pre-sonorant sandhi context.

\section{Further consequences of Laryngeal Relativism}

To summarize, the central claim of Laryngeal Relativism is that voice in sonorants is never phonological. This means that any phenomena which suggest a voicing activity of this class of segments must receive alternative solutions. This leads to a number of theoretical consequences.

Arbitrariness. One of the consequences is that we observe arbitrariness in the relation between phonology and phonetics. Laryngeal Relativism claims that WP and CPP, which have a phonetically identical distinction between fully voiced and voiceless unaspirated obstruents, have reversed marking of obstruents with respect to the laryngeal distinction. WP is an L-system $\left(\mathrm{C}^{\mathrm{L}}\right.$ vs. $\left.\mathrm{C}^{\mathrm{o}}\right)$, while $\mathrm{CPP}$ is an $\mathrm{H}$-system $\left(\mathrm{C}^{\mathrm{H}}\right.$ vs. $\left.\mathrm{C}^{\mathrm{o}}\right)$. Their phonological marking predicts that only in $\mathrm{CPP}$ can word-final obstruents be realized as voiced in front of sonorants. This is due to the fact that this dialect is deprived of phonological voicing. All its voicing is either spontaneous (vowels and sonorant consonants), or interpretational (enhanced passive voicing), but not active. WP, on the other hand, has both spontaneous (sonorants) and active voicing (voiced obstruents). Thus, $|\mathrm{H}|$ does not have to produce aspiration, while full voicing comes from either $\mathrm{C}^{\mathrm{L}}$ or $\mathrm{C}^{\circ}$. The arbitrariness becomes an obvious option only if phonological practice is freed from the bi-uniqueness bias discussed earlier, and only if phonological representations are strictly privative. In acquisition, the learner who is exposed to a two-way laryngeal distinction like in Polish, has to decide which of the two series is to be marked, thus establishing a spell-out relation, which is then used in production. The choice is not entirely arbitrary, because the whole system must be compatible with the phonetic patterns. Pre-sonorant sandhi voicing, or its absence, could be one of the decisive factors as to which phonetic category is actively represented in phonology and which one is to be a mere interpretation of the unmarked.

Emergent features. Arbitrariness of the relation between phonetic and phonological categories inevitably leads to an emergent character of phonological categories. They may still be universal (Mielke 2008), but cannot be 
innate, with pre-specified phonetic substance. It should be noted that the phonetic categories such as those along a VOT continuum (2) are provided by nature. The phonological marking is a decision (at acquisition) which of the articulatory or acoustic targets are to be marked when phonological distinctions within a particular 'space', for example, laryngeal domain, are to be made. The Relativist analysis of FOD and RVA in the two Polish dialects suggests that in fact it does not matter which series is marked. What is important is that the distinction between the two series is made in some way, and that it persists in strong positions and is lost in weak ones. Whether this is a property of only those domains in which a two-way distinction is made, or it can be extended to other domains, e.g., manner or place, is a matter of research.

No [voice] in a voice language. The analysis of Polish demonstrates that [voice]/L is not a necessary part of the so-called 'voice' languages, contrary to what the criteria in (1) tell us. It is tempting to look further into the linguistic status of [voice]/L. What prevents a radical elimination of this property at this stage is not only the analysis of pre-sonorant voicing proposed in this paper, which hinges on the presence of [voice]/L in WP, but also typological considerations. Reference to [voice]/L may be necessary in three-way contrast systems like Thai. It should be stressed, however, that what is meant as "presence of [voice]/L in WP and Thai, merely means that the phonetic series of fully voiced obstruents may go with phonological marking. Relativism and arbitrariness require that this possibility be available in linguistic systems. Thus, a complete elimination of [voice]/L is theoretically impossible in this model at this stage. Though, the property of full voicing might have a different phonological representation than we assume today.

In this respect, Laryngeal Relativism differs from theoretical proposals which reject the existence of voicing properties. One such proposal is Schwartz $(2016,113)$, in which the claim that voiced obstruents must not be marked phonologically is derived from the tenets of Modulation Theory (Traunmüller 1994). Generally, the theory assumes that phonological specification involves modulation of the carrier signal. The latter is defined as periodic signal with a schwa-like formant structure. Thus, the carrier signal is inherently voiced and involves neutral settings of the vocal tract. Since voicing is part of the carrier signal, the argument goes, voicing in obstruents is always unmarked, because it does not constitute a modulation. The main problem with this interpretation of Modulation Theory from the perspective of Laryngeal Relativism is that it suffers from the bi-uniqueness bias which this paper rejects: that phonetics (here acoustic signal) unam- 
biguously and directly informs us of the phonological representation. It also appears to be a programmatic opposite to the approaches in which every voiced segment is given the phonological feature [voice] (e.g., Itô et al. 1995). A different interpretation of the same Modulation Theory is offered in Harris $(2009,14)$, where he talks of 'disunity of voice' (cf. (3)), in that this property depends on segment types, phonological contexts and types of languages. For Harris, fully voiced obstruents in 'voice' languages must have a laryngeal category because they constitute a modulation of the default voicelessness in obstruents. In this sense, Harris is a laryngeal realist. It is not difficult to see how Relativism is different from the two approaches: while carrier signal modulations are linguistically significant, they need not be always a result of phonological marking, they may also be a 'reaction to' phonological marking in the contrastive congener.

Even smaller phonology. Government Phonology is sometimes described as 'small' (Scheer 2015a), as in 'small is beautiful'. Looking only at the melodic level, which is in focus in this paper, phonological activity is indeed restricted to privative representation and very limited computation. The only phonological processes recognized in GP are composition, that is, addition of elements, e.g., under spreading, and decomposition of representation under weak licensing, e.g., delaryngealization. The analyses of FOD, and especially the non-spread take on RVA in Polish (9), suggest that only decomposition is needed to account for all the relevant laryngeal phenomena in question. Thus, phonology can be even smaller than it is currently assumed, at least with respect to laryngeal phenomena. Delaryngealization is the only mechanism left which is phonologically controlled. It is again tempting to see if even this vestige of computation could be eliminated, as it is to some extent rejected in some proposals which attempt to capture incomplete neutralization phonologically. We will look at these proposals briefly in the following section. An alternative proposal concerning IN will be made, in which the categories responsible for laryngeal contrasts may in fact be deleted.

Exceptional systems. What also needs to be emphasized here is the advantage of Laryngeal Relativism in dealing with such exceptional systems as Dutch, or Durham English which have been claimed to be 'voice' languages phonologically. It is demonstrated in Cyran (2014) that both systems mentioned above are easily interpretable as 'voice' languages only at the phonetic level, but as H-systems phonologically. The H-analysis of Dutch is corroborated in van der Hulst (2015). At this stage, we can also say that the Swedish system, with both full voicing and aspiration, is not as problematic for Laryngeal Relativism as it is for Realism, in which both 
phonetic categories must be associated with phonological ones (Beckman et al. 2011). Since, the phonetic categories are indicative only of the phonetic side of the system, all that needs to be done is an analysis which would allow us to establish which of the two categories is in fact phonologically marked. However, doing that here would take us beyond the scope of this paper. The prediction that may be formulated at this point concerning Swedish is that there must be some phonetic reason why this language goes for maximal dispersion rather than for sufficient phonetic distance.

\section{Incomplete neutralization and Laryngeal Relativism}

Let us briefly look at the remaining question of incomplete neutralization in Polish and the fact that the distinction between lexically voiced and lexically voiceless obstruents in Polish seems to persist not only in FOD and RVA but also CPP sandhi (Strycharczuk 2012a,b). Phonological analyses of laryngeal phenomena often side-step incomplete neutralization (IN). ${ }^{18}$ There are a few reasons why this is so. Firstly, IN concerns statistically significant but often minute traces of the lexical distinctions which also happen to be difficult to detect in perceptual experiments. Secondly, there is an on-going methodological debate concerning adequate control for potentially contaminating factors (e.g., Jassem \& Richter 1989; Fourakis \& Iverson 1984; Kohler 2012). The history of IN studies shows that each new study reveals methodological flaws in the previous ones, while producing their own as well (see e.g., Röttger et al. 2014). Finally, the so-called neutralization might in effect concern other properties of phonological representation than the laryngeal specification, and the whole enterprise might turn out to be misguided (Kohler 2007; 2012). What follows is a number of comments and potential suggestions rather than a concrete proposal. In my view, the jury is still out on the issue of phonological significance of IN.

The first comment that can be made is that privative models like Element Theory with the standard assumption that assimilation sometimes involves element spreading, fair only a little better in allowing for IN than binary ones. In the latter, FOD involves a replacement of [+voice] with [-voice], with an unambiguously identical implementation of the derived devoiced obstruent and the lexically voiceless one. RVA, on the other hand, involves replacements in both directions, since the assimila-

18 There are, however, models which are built explicitly on the assumption that IN is a fact which must find a reflection in phonological representation (e.g., Schwartz 2016). 
tions in Polish are symmetrical, cf. prośba [prozba] 'a request' vs. tchu [txu] 'breath.GEN.SG.' (4). In Element Theory, it will be recalled, the standard FOD process turns $\mathrm{C}^{\mathrm{L}}$ into $\mathrm{C}^{\mathrm{o}}$, which is no different from the lexically unmarked obstruents. In RVA, on the other hand, delaryngealization and spreading are in fact leading to the same conclusion: IN is not expressed in any obvious way.

Some improvement, it seems, comes with the proposal in this paper that all RVA can be accounted for without reference to spreading. It is all down to phonetic interpretation and co-articulation. If a sequence $\mathrm{C}^{\mathrm{o}}-\mathrm{C}^{\mathrm{L}}$ (prośba) is phonetically interpreted as such - without spreading - then one may expect some variation and that the co-articulation may not be always complete. This, however, does not explain assimilations involving delaryngealization, e.g., $\mathrm{C}^{\mathrm{L}}-\mathrm{C}^{0} \rightarrow \mathrm{C}^{0}-\mathrm{C}^{0}$ because there is nothing in the first obstruent that might account for some difference with respect to the second one. The same problem concerns FOD and word-final delaryngealization.

I will first discuss two very similar approaches present in the literature in which the above problems are overcome by claiming that we are not dealing with any delaryngealization at all. The category responsible for the laryngeal contrast stays in the representation. ${ }^{19}$ One of the proposals is called 'turbidity' and is part of Optimality Theory tradition (van Oostendorp 2008), while the other one is a Radical CV Phonology (RcvP) proposal (van der Hulst 2015). Both proposals can be summarized in the following way: the laryngeal categories are not lost from the representation, but they are for some reason not implemented phonetically. Nevertheless, the phonological difference is there, and this is what brings about the minute phonetic distinctions.

The dilemma of compromising delaryngealization with incomplete neutralization can be represented graphically as in (11). The delaryngealized consonant (11b) is formally identical to the lexically unmarked one (11c), because a $\mathrm{C}$ with an unlicensed laryngeal category is the same from the point of view of phonetic implementation as the lexically unmarked C.

(11) a. marked b. delaryngealized c. lexically unmarked

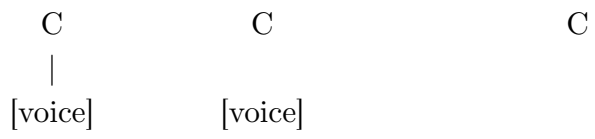

${ }^{19}$ Recall that this option was mentioned above, as it has the potential of eliminating computation in laryngeal phonology altogether. 
Van Oostendorp $(2008,8)$ uses a version of Turbidity Theory (Goldrick 2000 ) in which autosegmental association lines are in fact viewed as two different types of relations. One of them is called projection, and refers to an abstract, structural relationship holding between a segment and the feature (licensing). The other relation, pronunciation is about the output realization of structure. Thus, it may be said in this theory that a feature is licensed but not pronounced, due to the fact that the pronunciation relation between a feature and a segment might be missing. FOD is then described as a situation in which [voice] cannot entertain a pronunciation relation with an obstruent in the coda. (12) illustrates the relevant distinctions. It is clear the IN is due to the fact that the delaryngealized obstruent is in fact not deprived of the feature but one of the relations is missing: the one responsible for the pronunciation of the category $(12 \mathrm{~b})$. It is nonetheless different from (12c).

(12) a. marked b. delaryngealized c. lexically unmarked

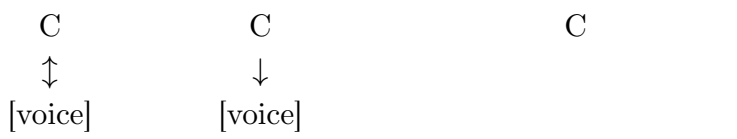

The idea of 'turbidity' is very much in the spirit of Laryngeal Relativism: what else can be more relative than having a licensed category which will however be unpronounced? It would go beyond the scope of this paper to discuss the potential consequences of this idea, or how it could be adapted in Element Theory. The model would need to be changed to be able to see and express the difference between licensing and phonetic interpretability, which it does not at the moment. Suffice it to say, that intervocalic absence of aspiration in English while the laryngeal distinction is clearly maintained and surfaces as passively voiced vs. voiceless unaspirated, could be taken as an example of a category being licensed but not interpreted phonetically.

The proposal in van der Hulst (2015) is very much in the same vain even though the model is quite different. It is proposed that all two-way systems, both 'voice' and 'aspiration' ones, are underlyingly represented as unmarked $\emptyset$ vs. [fortis]. While $\emptyset$ can to some extent be equated with 'lenis', the property [fortis] can be roughly, but perhaps aptly, defined as 'resistance to voicing'. Thus, the phonetic correlates of this property are all or some of the articulatory gestures that inhibit vocal cord vibration (cf. Halle \& Stevens 1971). The distinction between 'voice' and 'aspiration' languages is made by means of language specific, phonological and context dependent enhancement rules. For example, English would enhance [fortis] with [spread] before stressed vowels, but not in other contexts. This 
produces an 'aspiration' language in which the distinction is in fact $\emptyset$ vs. [fortis], [spread] in the enhancement context. A 'voice' language like Polish has, roughly speaking, the enhancement rule $\emptyset \rightarrow$ [voice] / _ vowel, and effectively a distinction [voice] vs. [fortis]. Crucially, there is no delaryngealization in neutralization contexts. Simply, these are the contexts in which enhancement does not apply. Thus, FOD in Polish is a case of absence of enhancement of $\emptyset$ with [voice], but representationally, the two series of obstruents in word-final context in Polish are different. They are the unenhanced $\emptyset$ vs. [fortis]. One is voiceless because it is not enhanced with [voice], while the other is voiceless by definition. Nonetheless, the two series are still representationally different.

There are two reasons why this proposal might be incompatible with Laryngeal Relativism. Firstly, it imposes uniformity of underlying representation $\emptyset$ vs. [fortis] on all kinds of two-way systems, which is very much in the spirit of Keating (1984), except that we are dealing with a privative system, at least at the underlying level. Another problematic aspect of this proposal is the phonological status of enhancement rules (cf. Stevens \& Keyser 1989). It is rather incompatible with Element Theory, and especially its view on privativity. Finally, if [fortis] were to survive in word-final context in Polish, it would be difficult to explain both pre-obstruent and especially pre-sonorant voicing of the lexical [fortis] segments: they should remain voiceless, unless phonetic interpretation in RcvP is supplemented with something like 'turbidity' mentioned above.

As an alternative to the two proposals above, I would like to suggest a different analysis, in which laryngeal categories are deleted, but they leave a trace, parallel to syntactic traces. The problem of IN is not eating a cake and having it. The cake is eaten. What is left is crumbs. Given that subsegmental primes may be organized hierarchically (Clements 1985; Clements \& Hume 1995), an idea which is also employed in some Element Theory work (e.g., Harris 1994, 129), it could be proposed that only laryngeally specified obstruents possess a laryngeal node (13a), and that delinking of laryngeal categories does not affect the tree structure (13b). The lexically non-specified obstruents, on the other hand, simply lack the node (13c). The illustration shows the distinctions in WP only. The CPP representations will involve the element $|\mathrm{H}|$.

(13) a. marked

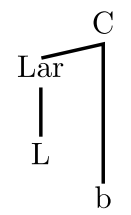

b. delaryngealized

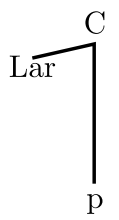

c. lexically unmarked

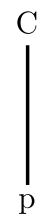


The difference between (13b) and (13c) cannot be used distinctively because contrasts are defined by elements/features. The post-deletion structure in $(13 \mathrm{~b})$, however, may be assumed to be responsible for the minute phonetic traces of the lexical laryngeal distinctions which may be observed in FOD and RVA. This proposal avoids the situation in which a distinctive category which is present in the representation does not contribute to a distinction at spell-out. It should be added that the structural trace analysis of IN is truly available only under the assumption that there is no spreading in assimilations. Then, all assimilation is co-articulatory and the targets may show traces of their lexical identity.

\section{Conclusion}

In this paper I have looked at some consequences of applying a stringent version of Kaye's Phonological Epistemological Principle, which claims that phonological knowledge, including decisions on what categories are used and how, comes only from phonological behaviour. I have restricted the meaning of 'phonological behaviour' solely to the expression of categorical distinctions. This is because surface patterns which suggest phonological processes are contradictory and misleading. For example, the symmetrical nature of RVA in Polish, if taken at face value would suggest that the phonological representation of the laryngeal distinction among obstruents should be binary, because there is assimilation to a voiced as well as to a voiceless obstruent. Additionally, the celebrated phenomenon of presonorant voicing in sandhi, which occurs in one dialect group of Polish, should suggest that sonorants spread a voicing property onto obstruents, which is a very common scenario in the literature.

As a consequence of the strict view on categoryhood, sonorants, including vowels, are disallowed to possess any voicing properties. A new analysis of CPP pre-sonorant voicing gave rise to a new model - Laryngeal Relativism - in which the relation between phonetic and phonological categories is arbitrary. This in turn leads to a rejection of commonly used criteria for establishing types of laryngeal systems and their representation in Laryngeal Realism. Both FOD and RVA can be given alternative analyses which are not based on [voice]/L deletion or spreading, respectively. This further weakens the traditional criteria in (1).

One of the extreme consequences of Laryngeal Relativism is that the so-called 'voice' languages, which feature FOD and RVA might in fact not even possess the phonological feature [voice], or a parallel category, e.g., $|\mathrm{L}|$ at their disposal. However, elimination of that category from all 
phonological systems across the board would be incompatible with the basic tenets of Laryngeal Relativism.

Finally, I also attempted to respond to the problem of incomplete neutralization in laryngeal phonology by allowing for as much phonological difference between the derived delaryngealized obstruent and the lexically neutral one as the phenomenon seems to deserve. It is a mere trace of lexical marking which is expressed structurally rather than by means of distinctive categories.

\section{References}

Avery, Peter and William Idsardi. 2001. Laryngeal dimensions, completion and enhancement. In T. A. Hall (ed.) Distinctive feature theory. Berlin \& New York: Mouton de Gruyter. 41-70.

Backley, Phillip. 2011. An introduction to Element Theory. Edinburgh: Edinburgh University Press.

Bárkányi, Zsuzsanna and Zoltán G. Kiss. 2015. Why do sonorants not voice in Hungarian? And why do they voice in Slovak? In K. É. Kiss, B. Surányi and É. Dékány (eds.) Approaches to Hungarian 14: Papers from the 2013 Piliscsaba conference. Amsterdam \& Philadelphia: John Benjamins. 65-94.

Beckman, Jill, Pétur Helgason, Bob McMurray and Catherine O. Ringen. 2011. Rate effects on Swedish VOT: Evidence for phonological overspecification. Journal of Phonetics 39. 39-49.

Beckman, Jill, Michael Jessen and Catherine O. Ringen. 2013. Empirical evidence for laryngeal features: aspirating vs. true voice languages. Journal of Linguistics 49. 259-284.

Bethin, Christina. 1984. Voicing assimilation in Polish. Journal of Slavic Linguistics and Poetics 29. 17-32.

Bethin, Christina. 1992. Polish syllables. The role of prosody in phonology and morphology. Columbus: Slavica.

Booij, Geert. 1995. The phonology of Dutch. Oxford: Oxford University Press.

Botma, Bert. 2004. Phonological aspects of nasality. An element-based dependency approach. Doctoral dissertation. University of Amsterdam.

Botma, Bert. 2011. Sonorants. In M. van Oostendorp, C. Ewen, E. Hume and K. Rice (eds.) The Blackwell companion to phonology. Malden, MA \& Oxford: Wiley-Blackwell. 171-194.

Cho, Taehong and Peter Ladefoged. 1999. Variations and universals in VOT: Evidence from 18 endangered languages. Journal of Phonetics 27. 207-222.

Chomsky, Noam and Morris Halle. 1968. The sound pattern of English. New York: Harper \& Row.

Clements, George N. 1985. The geometry of phonological features. Phonology Yearbook 2. $225-252$.

Clements, George N. and Elizabeth Hume. 1995. The internal organization of speech sounds. In J. A. Goldsmith (ed.) The handbook of phonological theory. Cambridge, MA \& Oxford: Blackwell. 245-306. 
Cyran, Eugeniusz. 2011. Laryngeal realism and laryngeal relativism: Two voicing systems in Polish? Studies in Polish Linguistics 6. 45-80.

Cyran, Eugeniusz. 2014. Between phonology and phonetics. Polish voicing. Berlin \& New York: De Gruyter Mouton.

De Schutter, Geert and Johan Taeldeman. 1986. Assimilatie van Stem in de Zuidelijke Nederlandse Dialekten. In M. Devos and J. Taeldeman (eds.) Vruchten van z'n akker: opstellen van (oud-) medewerkers en oud-studenten voor Prof. V. F. Vanacker. Ghent: Seminarie voor nederlandse Taalkunde. 91-133.

Dinnsen, Daniel and Jan Charles-Luce. 1984. Phonological neutralization, phonetic implementation, and individual differences. Journal of Phonetics 12. 49-60.

Docherty, Gerard J. 1992. The timing of voicing in British English obstruents. Berlin \& New York: Foris.

Ernestus, Mirjam. 2000. Voice assimilation and segment reduction in casual Dutch. Doctoral dissertation. Free University of Amsterdam/Holland Institute of Generative Linguistics.

Fourakis, Marios and Gregory Iverson. 1984. On the 'incomplete neutralization' of German final obstruents. Phonetica 41. 140-149.

Goldrick, Matt. 2000. Turbid output representations and the unity of opacity. In M. Hirotani, A. Coetzee, N. Hall and J.-Y. Kim (eds.) Proceedings of NELS 30. Amherst: University of Massachusetts. 231-245.

Gussmann, Edmund. 1992. Resyllabification and delinking: The case of Polish voicing. Linguistic Inquiry 23. 29-56.

Gussmann, Edmund. 2007. The phonology of Polish. Oxford: Oxford University Press.

Halle, Morris and Kenneth N. Stevens. 1971. A note on laryngeal features. Quarterly Progress Report, Research Laboratory of Electronics 101. 198-213.

Harris, John. 1990. Segmental complexity and phonological government. Phonology 7. 255-300.

Harris, John. 1994. English sound structure. Oxford \& Cambridge, MA: Blackwell.

Harris, John. 2009. Why final obstruent devoicing is weakening. In K. Nasukawa and P. Backley (eds.) Strength relations in phonology. Berlin \& New York: Mouton de Gruyter. 9-46.

Harris, John and Geoff Lindsey. 1995. The elements of phonological representation. In J. Durand and F. Katamba (eds.) Frontiers of phonology: Atoms, structures, derivations. Harlow: Longman. 34-79.

Helgason, Pétur and Catherine Ringen. 2008. Voicing and aspiration in Swedish stops. Journal of Phonetics 36. 607-628.

Honeybone, Patrick. 2002. Germanic obstruent lenition: Some mutual implications of theoretical and historical phonology. Doctoral dissertation. University of Newcastle upon Tyne.

Honeybone, Patrick. 2005. Diachronic evidence in segmental phonology: The case of obstruent laryngeal specifications. In M. van Oostendorp and J. van de Weijer (eds.) The internal organization of phonological segments. Berlin \& New York: Mouton de Gruyter. 319-354.

Hualde, José and Marianna Nadeu. 2011. Lenition and phonemic overlap in Rome Italian. Phonetica 68. 215-242. 
Hulst, Harry van der. 2015. The laryngeal class in RcvP and Voice phenomena in Dutch. In J. Caspers, Y. Chen, W. Heeren, J. Pacilly, N. O. Schiller and E. van Zanten (eds.) Above and beyond the segments: Experimental linguistics and phonetics. Amsterdam \& Philadelphia: John Benjamins. 323-349.

Itô, Junko, Armin Mester and Jaye Padgett. 1995. Licensing and underspecification in Optimality Theory. Linguistic Inquiry 26. 571-613.

Iverson, Gregory K. and Joseph C. Salmons. 1995. Aspiration and laryngeal representation in Germanic. Phonology 12. 369-396.

Iverson, Gregory K. and Joseph C. Salmons. 2003. Laryngeal enhancement in early Germanic. Phonology 20. 43-74.

Iverson, Gregory K. and Joseph C. Salmons. 2007. Domains and directionality in the evolution of German final fortition. Phonology 24. 121-145.

Jansen, Wouter. 2004. Laryngeal contrast and phonetic voicing: A laboratory phonology approach to English, Hungarian, and Dutch. Doctoral dissertation. Rijksuniversiteit Groningen.

Jansen, Wouter. 2007. Dutch regressive voicing assimilation as a 'low level phonetic process': Acoustic evidence. In van de Weijer \& van der Torre (2007, 125-151).

Jassem, Wiktor and Lutoslawa Richter. 1989. Neutralization of voicing in Polish obstruents. Journal or of Phonetics 17. 317-325.

Jessen, Michael. 1998. Phonetics and phonology of tense and lax obstruents in German. Amsterdam \& Philadelphia: John Benjamins.

Kaye, D., Jonathan. 2005. GP, I'll have to put your flat feet on the ground. In H. Broekhius, N. Corver, R. Huybregts, U. Kleinhenz and J. Koster (eds.) Organizing grammar. Studies in honor of Henk van Riemsdijk. Berlin \& New York: Mouton de Gruyter. $283-288$.

Kaye, Jonathan D., Jean Lowenstamm and Jean-Roger Vergnaud. 1985. The internal structure of phonological elements: A theory of charm and government. Phonology Yearbook 2. 305-328.

Kaye, Jonathan D., Jean Lowenstamm and Jean-Roger Vergnaud. 1990. Constituent structure and government in phonology. Phonology 7. 193-231.

Keating, Patricia A. 1984. Phonetic and phonological representation of stop consonant voicing. Language 60. 286-319.

Kohler, Klaus. 1984. Phonetic explanation in phonology: The feature fortis/lenis. Phonetica 41. $150-174$.

Kohler, Klaus. 2007. Beyond Laboratory Phonology: The phonetics of speech communication. In Solé et al. (2007, 41-53).

Kohler, Klaus. 2012. Neutralization?! The phonetics-phonlogy issue in the analysis of wordfinal obstruent voicing. In D. Gybbon, D. Hirst and N. Campbell (eds.) Rhythm, melody and harmony in speech. Studies in honour of Wiktor Jassem. Poznań: Polish Phonetic Association. 171-180.

Krämer, Martin. 2001. On obstruent voicing in Breton, German, and Italian. In A. Holmer, J.-O. Svantesson and A. Viberg (eds.) Proceedings of the 18th Scandinavian Conference of Linguistics. Lund: Lund University Press. 39-55.

Liljencrants, Johan and Björn Lindblom. 1972. Numerical simulation and vowel quality systems: the role of perceptual contrast. Language 48. 839-862. 
Lisker, Leigh and Arthur Abramson. 1964. A cross-language study of voicing in initial stops: Acoustical measurements. Word 20. 384-422.

Michalski, Grzegorz. 2008. Representational handling of Poznań-Cracow voicing in Government Phonology. Poznań Studies in Contemporary Linguistics 44. 379-399.

Mielke, Jeff. 2008. The emergence of distinctive features. Oxford: Oxford University Press.

Oostendorp, Marc van. 2008. Incomplete devoicing in formal phonology. Lingua 118. $1362-1374$.

Port, Robert F., Fares Mitleb and Michael L. O'Dell. 1981. Neutralization of obstruent voicing in German is incomplete. Journal of the Acoustical Society of America 70. S13, F10.

Port, Robert F. and Michael O'Dell. 1985. Neutralization of syllable-final voicing in German. Journal of Phonetics 13. 455-471.

Pöchtrager, Markus Alexander and Jonathan Kaye. 2013. GP2.0. SOAS Working Papers in Linguistics and Phonetics 16. 51-64.

Rice, Keren. 1993. A re-examination of the feature [sonorant]: The status of 'sonorant' obstruents. Language 69. 308-344.

Röttger, Timo, Bodo Winter, Sven Grawunder, James Kirby and Marine Gice. 2014. Assessing incomplete neutralization of final devoicing in German. Journal of Phonetics 43. $11-25$.

Rubach, Jerzy. 1996. Nonsyllabic analysis of voice assimilation in Polish. Linguistic Inquiry 27. $69-110$.

Scheer, Tobias. 2015a. A world without voiced sonorants. Reflections on Cyran 2014 (Part 1). Studies in Polish Linguistics 10. 125-151.

Scheer, Tobias. 2015b. A world without voiced sonorants. Reflections on Cyran 2014 (Part 2). Studies in Polish Linguistics 10. 223-247.

Schwartz, Geoff. 2013. A representational parameter for onsetless syllables. Journal of Linguisitcs 49. 613-646.

Schwartz, Geoff. 2016. Representing non-neutralization in Polish sandhi-voicing. In J. Szpyra-Kozłowska and E. Cyran (eds.) Phonology, its faces and interfaces. Frankfurt am Main: Peter Lang. 103-121.

Schwartz, Jean-Luc, Luis-Jean Boë and Christian Abry. 2007. Linking Dispersion-Focalization Theory and the maximum utilization of the available distinctive features principle in a Perception-for-Action-Control Theory. In Solé et al. (2007, 104-124).

Slowiaczek, Louisa M. and Daniel A. Dinnsen. 1985. On the neutralizing status of Polish wordfinal devoicing. Journal of Phonetics 13. 325-341.

Solé, Marie J., Patrice S. Beddor and Manjari Ohala (eds.). 2007. Experimental approaches to phonology. Oxford: Oxford University Press.

Stevens, Kenneth N. 1972. The quantal nature of speech: Evidence from articulatory-acoustic data. In P. B. Denes and E. E. D. Jr. (eds.) Human communication: A unified view. New York: McGraw Hill. 51-66.

Stevens, Kenneth N. and Samuel J. Keyser. 1989. Primary features and their enhancement in consonants. Language 65. 81-106.

Strycharczuk, Patrycja. 2012a. Phonetics-phonology interactions in pre-sonorant voicing. Doctoral dissertation. University of Manchester. 
Strycharczuk, Patrycja. 2012b. Sonorant transparency and the complexity of voicing in Polish. Journal of Phonetics 40. 655-671.

Ternes, Elmar. 1970. Grammaire structurale du Breton de L'Ile de Groix. Heidelberg: Carl Winter Universitatsverlag.

Traunmüller, Hartmut. 1994. Conventional, biological, and environmental factors in speech communication: A modulation theory. Phonetica 51. 170-183.

Weijer, Jeroen Maarten van de and Erik Jan van der Torre (eds.). 2007. Voicing in Dutch. (De)voicing - Phonology, phonetics, and psycholinguistics. Amsterdam \& Philadelphia: John Benjamins.

Wheeler, Max. 1986. Catalan sandhi phenomena. In H. Andersen (ed.) Sandhi phenomena in the languages of Europe. Berlin \& New York: Mouton de Gruyter. 475-488.

Wierzchowska, Bożena. 1971. Wymowa polska [Polish pronunciation]. Warszawa: Państwowe Zakłady Wydawnictw Szkolnych.

Zonneveld, Wim. 2007. Issues in Dutch devoicing: Positional faithfulness, positional markedness and local conjunction. In van de Weijer \& van der Torre $(2007,1-40)$. 